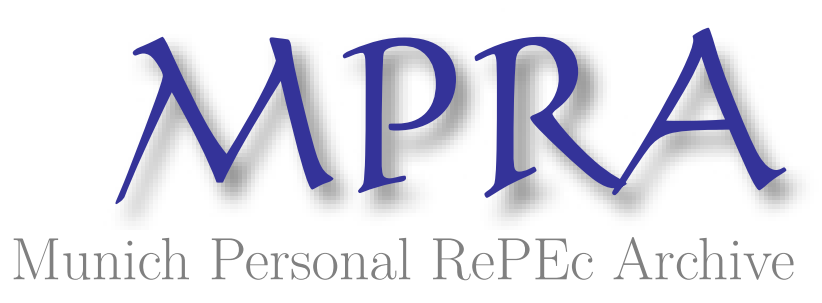

\title{
The Effect of External Incentives on Profits and Firm-Provided Incentives Strategy
}

Azar, Ofer H.

Ben-Gurion University of the Negev

2003

Online at https://mpra.ub.uni-muenchen.de/4456/

MPRA Paper No. 4456, posted 13 Aug 2007 UTC 
This is an early version of an article that is forthcoming in the Journal of Socio-Economics.

The final version of this article is available at http://dx.doi.org/10.1016/j.socec.2007.06.010

\title{
The Effect of External Incentives on Profits and Firm-Provided Incentives Strategy
}

\author{
Ofer H. Azar \\ Department of Business Administration \\ Ben-Gurion University of the Negev
}

The article examines the firm's choice of incentives when workers face additional incentives ("external incentives") to those provided by the firm, such as building reputation that improves the workers' prospects with other employers, or satisfaction from working well. Surprisingly, the firm might find it optimal to increase the incentives it provides following an increase in external incentives. Even if the firm reduces its incentives, however, total incentives unambiguously increase, leading to higher effort and profits. This implies that firms should try to increase the external incentives that their workers face; I suggest several ways firms can do so.

Keywords: Worker satisfaction; Personnel economics; External incentives; Worker reputation; Intrinsic motivation.

JEL classification codes: M52; M20; L20; J30; D21

\footnotetext{
* Ofer H. Azar, Department of Business Administration, School of Management, Ben-Gurion University of the Negev, P.O.B. 653, Beer Sheva 84105, Israel. Tel.: +972-8-6472675; Fax: +972-8-6477691. E-mail address: azar@som.bgu.ac.il. I thank James Dana and participants in the Industrial Organization Society Conference in Boston (2003) and in the EARIE 2003 conference in Helsinki for helpful discussions and comments. I also thank two anonymous referees for many helpful comments. Financial support from The Center for the Study of Industrial Organization at Northwestern University and from The Phillipe Monaster Center For Economic Research at Ben-Gurion University of the Negev is gratefully acknowledged.
} 


\section{Introduction}

The provision of optimal incentives by the firm received a lot of attention from economists in the last two decades. The basic problem is that of a single principal providing incentives to a single agent who has to perform a single task in a single period. Extensions of this basic problem include multiple principals with conflicting demands (see for example Bernheim and Whinston, 1986), multiple agents (see Holmstrom, 1982; Mookherjee, 1984), multiple tasks (for instance Holmstrom and Milgrom, 1991), and multiple periods (for example Rogerson, 1985).

Another possible extension is that of multiple incentives. At first, this issue seems trivial: providing several different incentives is equivalent to providing a single incentive that is equal to the sum of the different incentives. The problem becomes interesting, however, when one of the incentives is not provided by the firm (henceforth I denote this kind of incentives "external incentives," since they are external from the firm's perspective), and the firm has to determine how to adapt its own incentives to fit best these other incentives.

One example of external incentives is the psychological utility and satisfaction that workers derive from doing their job well. This is especially prevalent in jobs that require initiative and creativity. Most professors, for example, prefer writing a well-crafted and important article to writing a mediocre one even if they have no monetary or social rewards from the better article. Similarly, a manager takes pride in leading the firm to higher profits even if he is not rewarded for it monetarily. Obviously, the worker also takes into account the cost of the effort associated with better performance. The point, however, is that other things being equal, the worker often prefers to do his job well, because this gives him some sort of psychological utility. This implies that the worker's utility depends positively on his

performance level. This motivation for doing a good job is external from the firm's 
perspective since it comes from the worker's desire to work well and not from firm-provided incentives.

Another example for external incentives comes from reputation concerns: generally, workers want to build a reputation in order to improve their prospects with other employers. ${ }^{1}$ Anyone who attaches a positive probability to the event that he will change employers in the future (it does not matter whether the change is voluntary or imposed by the firm) has an incentive to perform well in order to be more attractive to prospective employers. Potential employers receive information about previous performance of the candidate from various sources. They ask for letters of reference from previous employers, and may also receive information from people they know who worked with the candidate. In addition, some performance signals are public, for example managers may be judged according to their firm's profits or stock performance. Other signals can be credibly conveyed by the worker on his curriculum vitae, such as recent salary and rank, how often he was promoted, and special recognition of excellent performance (e.g., winning the "employee of the year" award). The ability of future employers to obtain information on his current performance motivates the employee to perform well in his current job.

Satisfaction from working well and reputation building act to increase the worker's effort. Consequently, the external incentives and the firm-provided incentives act in the same direction, rather than contradict each other. The article analyzes the optimal choice of firmprovided incentives in the presence of such external incentives. It seems natural to expect that an increase in external incentives reduces the firm-provided incentives. Surprisingly, however, the analysis suggests that this is not always the case. How the firm should change

\footnotetext{
${ }^{1}$ Workers may also want to build a reputation in order to be promoted within the firm, but since the prospects of internal promotions and the monetary rewards to such promotions are determined by the firm, the motivation of promotion within the firm does not fit well the notion of "external incentives."
} 
its incentives following a change in external incentives turns out to depend on the secondorder derivative of the revenue function with respect to effort. The analysis also shows that profits are increasing in the amount of external incentives, suggesting that the firm should try to increase the external incentives its workers face.

The rest of the article is organized as follows: Section 2 presents the model, Section 3 solves for the equilibrium and analyzes how changes in external incentives affect effort, profits, revenues, and the optimal firm-provided incentives, and Section 4 concludes, giving several ideas how firms can increase the external incentives that their workers face.

\section{The Model}

The model developed below is aimed to be as simple as possible for two reasons. First, this makes the model more tractable, and makes it easier to see where the results come from. Second, one of the main goals of the paper is to illustrate the counter-intuitive result that an increase in external incentives does not necessarily imply a decrease in the optimal level of firm-provided incentives. If this point can be shown using a simple model, it obviously can also be shown with more complicated models, but the reverse is not necessarily true.

The game between the firm and the worker involves two stages. In the first stage the firm chooses how much incentives to provide to the worker, and in the second stage the worker chooses his effort level. Since effort level (denoted by e) has no natural scale, we can choose $\mathrm{e}=0$ to be the effort minimizing level, and also scale effort in a way that makes the external 
incentives linear in effort level; let $\varepsilon_{0}+\varepsilon$ e be the external incentives for effort level e, where $\varepsilon$ $\geq 0 .^{2}$

Effort is observable by the firm, and therefore the firm may provide incentives to the worker to exert effort. ${ }^{3}$ I assume for simplicity that these incentives are also linear in effort. ${ }^{4}$

${ }^{2}$ For example, choose $\mathrm{e}=1$ to represent an arbitrary effort level above zero. Denote the external incentives for e $=0$ as $\varepsilon_{0}$ and for $\mathrm{e}=1$ as $\varepsilon_{0}+\varepsilon$. Now define $\mathrm{e}=2$ to be the effort level that results in external incentives of $\varepsilon_{0}+$ $2 \varepsilon$ and so on. As a result, the external incentives are linear in effort level.

${ }^{3}$ There are several good reasons to adopt the assumption that effort is observable by the firm. First, it simplifies the analysis. Second, even if the firm does not observe effort directly, if it observes its revenues and the revenues are a deterministic function of effort, then the firm can figure out the effort level accurately, which is equivalent to effort being observable. For example, a firm might not observe the effort of a production worker or a salesperson directly, but it knows how much was produced and sold, and this can provide the firm information about the effort level. Third, it can be shown that with risk-neutral firm and worker, even if the firm does not observe effort exactly but instead only observes $\mathrm{e}+\beta$, where $\beta$ is some noise with zero expectation, the results remain exactly the same. The reason is that when the worker and the firm maximize their expected utility and profits, the term $\mathrm{E}(\beta)$ that appears in the utility and profit functions is equal to zero and therefore it drops and the analysis becomes identical to the one in the paper.

${ }^{4}$ The linearity assumption makes it much easier to see how an increase in external incentives affects the optimal choice of incentives by the firm, since both incentive types are then linear in effort and therefore have a clear measure of the sensitivity of incentives to effort - the slope of the linear function. It becomes difficult to analyze what happens to the sensitivity of incentives to effort when it cannot be captured by a single parameter as in the linear functions assumed. Moreover, without assuming a specific functional form of the firm incentives, the worker's choice of effort cannot be explicitly found, which is necessary in order to substitute it in the firm's maximization problem. It is also worth mentioning that some of the theoretical literature in this area assumes that if effort is observable then the firm should offer a contract in which the worker receives zero compensation unless he exerts exactly the effort level that the firm wants to implement. From a theoretical perspective, this assumption makes sense. From a practical perspective, however, this type of "all-or-nothing" contract is less plausible and is not observed much in the real world, even in cases where effort can be measured quite well by 
The firm-provided incentives are equal to $\phi_{0}+\phi e$. The utility function of the worker is quasilinear in money, and the cost of effort is $\mathrm{e}^{2}$, so the worker's utility function becomes:

$$
\mathrm{u}(\mathrm{e})=\varepsilon_{0}+\varepsilon \mathrm{e}+\phi_{0}+\phi \mathrm{e}-\mathrm{e}^{2} .
$$

The worker chooses to remain in his job only if he obtains at least his reservation utility, which is denoted by $\mathrm{U}_{0}$ and is known to the firm.

The revenues that the output of the worker yields depend on the effort level, and are denoted by $\mathrm{r}(\mathrm{e})$, where $\mathrm{r}$ is a twice-continuously-differentiable function satisfying $0 \leq \mathrm{r}^{\prime}(\mathrm{e}) \leq$ $\mathrm{R}$ and $\mathrm{r}^{\prime \prime}(\mathrm{e})<2$ for all e. ${ }^{5}$ The condition $\mathrm{r}^{\prime \prime}(\mathrm{e})<2$ ensures that the second-order sufficient

the worker's output, for example in the case of production workers or salespeople. There may be several reasons for this, including social norms about what is considered an appropriate compensation scheme, union involvement in the bargaining process, minimum wage laws, worker feelings that this type of contract is unfair, noisy relationship between effort and output and more. While it is possible to put some of these ingredients in the model and achieve the result that the optimal contract is not of the "all-or-nothing" type (with an "all-ornothing" contract the model does not allow to analyze the issues on which this article focuses), I did not want to make the model more complicated than necessary, so I assume that the firm can only choose linear incentive schemes.

${ }^{5}$ One example when we can have a convex revenue function is when the job requires several tasks, and the most productive tasks can be done only if the less-productive ones were completed as well. Exerting only some effort then results in only the less-productive tasks being completed, while more effort allows the high-productive tasks to be done, thus creating increasing returns to effort. For example, consider a lawyer who is employed by a law-firm. The firm's revenues depend on the success of the lawyer in a litigation against another firm, either because the client pays a percentage of the amount won, or because future revenues depend on reputation, which depends on success. The lawyer can study the facts in this case (less-productive effort), and he can think really hard how to win this case (more productive effort). That is, the significant contribution of the lawyer to revenues is when he not only studies the case, but also puts more effort and thinks about the case really hard. The lawyer, however, must study the case in order to be able to think hard how to win it; he cannot do the latter without the former. Thus, after he studies the case, the additional effort required to think hard about it is what brings the 
condition for profit maximization is met for all parameter values. The condition $\mathrm{r}^{\prime}(\mathrm{e}) \leq \mathrm{R}$ (for some finite upper bound $\mathrm{R}$ ) ensures that the first-order condition for utility maximization has a solution. Assumption 1 summarizes the assumptions about $\mathrm{r}(\mathrm{e})$ :

Assumption 1. r(e), the revenues as a function of effort, is twice continuously differentiable and satisfies $0 \leq r^{\prime}(e) \leq R$ and $r^{\prime \prime}(e)<2$ for all $e$.

The reason that $r$ is increasing in e can be that more effort of the worker results in higher quantity of output, or in higher quality of the good or service, or both. For example, if quality is fixed but quantity (denoted by q) is a function of effort, the firm's revenues ${ }^{6}$ are $r(e)=$ $\mathrm{pq}(\mathrm{e})$, so $\mathrm{r}^{\prime}(\mathrm{e})=\mathrm{pq}^{\prime}(\mathrm{e}) \geq 0$ and $\mathrm{r}^{\prime \prime}(\mathrm{e})=\mathrm{pq} \mathrm{q}^{\prime}(\mathrm{e})$. We can think about $\mathrm{q}$ as a production function whose input is effort. For example, a worker who produces simple goods might be able to work faster and produce more units if he exerts more effort, whereas the quality is fixed. The sign of $r^{\prime \prime}(e)$ in this case is equal to the sign of q"(e), which is negative, zero, or positive depending whether the production function exhibits decreasing, constant, or increasing returns to effort, respectively.

Alternatively, quantity may be fixed but effort improves the quality of the good or service and therefore increases the price the consumer is willing to pay for each unit. For

most revenues, resulting in increasing returns to effort. A similar argument can be made with respect to an accountant planning a tax strategy for a big firm. He has to study the firm's environment and financial statements carefully (less-productive effort) in order to be able to think hard how to cut the firm's taxes (more productive effort).

${ }^{6}$ I assume for simplicity that the change in quantity due to the choice of effort does not affect price. This is the case if the firm is in a perfectly competitive market, and therefore the price is not affected by the firm's output, or if the firm has many workers and thus the effect of any single worker on the market price (through his effect on total quantity) is negligible. 
example, the price a consumer is willing to pay for one hour of a lawyer, a consultant, an accountant, or a similar service provider, is increasing in the effort that the service provider exerts. Denoting the price the firm can charge as a function of effort as $p(e)$, we then have $r(e)=p(e) q$, with $r^{\prime}(e)=p^{\prime}(e) q \geq 0$ and $r^{\prime \prime}(e)=p^{\prime \prime}(e) q$. In this case, the sign of $r^{\prime \prime}(e)$ is equal to the sign of $\mathrm{p}^{\prime \prime}(\mathrm{e})$, and can again be either positive, negative, or zero.

Similarly, we can analyze the case where both quality and quantity change with effort: $r(e)=p(e) q(e)$. It then follows that $r^{\prime}(e)=p^{\prime}(e) q(e)+p(e) q^{\prime}(e)$ and $r^{\prime \prime}(e)=p "(e) q(e)+$ $2 p^{\prime}(e) q^{\prime}(e)+p(e) q^{\prime \prime}(e)$. To illustrate how in this example we can get any sign for $r^{\prime \prime}(e)$, consider the simple functions $\mathrm{p}(\mathrm{e})=\mathrm{ae}^{\mathrm{x}}$ and $\mathrm{q}(\mathrm{e})=\mathrm{be}^{\mathrm{y}}$, where $\mathrm{a}>0$ and $\mathrm{b}>0$. We then have $r(e)=p(e) q(e)=a b e^{x+y}$, so $r^{\prime}(e)=(x+y) a b e^{x+y-1}$ and $r^{\prime \prime}(e)=(x+y)(x+y-1) a b e^{x+y-2}$. We assumed that $\mathrm{r}^{\prime}(\mathrm{e}) \geq 0$, implying that $\mathrm{x}+\mathrm{y} \geq 0$. If $\mathrm{x}+\mathrm{y}=0$ then $\mathrm{r}^{\prime \prime}(\mathrm{e})=0$, and otherwise the sign of $\mathrm{r}^{\prime \prime}(\mathrm{e})$ is equal to the sign of $(\mathrm{x}+\mathrm{y}-1)$, which can be positive, negative, or zero. In the analysis below I retain the general form of $\mathrm{r}(\mathrm{e})$ (it does not matter for the analysis from which of the cases discussed above it comes), and assume the firm has no costs other than the worker's compensation. ${ }^{7}$ Therefore the firm's profits are given by

$$
\pi\left(\phi_{0}, \phi, e\right)=\mathrm{r}(\mathrm{e})-\phi_{0}-\phi \mathrm{e}
$$

\section{The Equilibrium}

The game is solved backwards, finding first the optimal effort level chosen by the worker and substituting it in the profit function to find the firm's choice of $\phi_{0}$ and $\phi$. Denote the equilibrium choices as $\mathrm{e}^{*}, \phi_{0}{ }^{*}$, and $\phi^{*}$. The following proposition describes the equilibrium:

\footnotetext{
${ }^{7}$ Adding a fixed cost of production will not change the results. Adding a per-unit cost of production will require to specify the exact functional relationship between effort, quantity, price, and cost, and will thus make the model less general and much more complex without adding insights on the issues on which this article focuses.
} 
Proposition 1. In equilibrium: (a) $e^{*}=\left(\phi^{*}+\varepsilon\right) / 2$,

(b) $\phi_{0}{ }^{*}=U_{0}-\varepsilon_{0}-\left(\phi^{*}+\varepsilon\right)^{2} / 4$,

(c) The value of $\phi^{*}$ is determined by the equation $\phi^{*}=r^{\prime}\left(e^{*}\right)=r^{\prime}\left[\left(\phi^{*}+\varepsilon\right) / 2\right]$, and for a given value of $\varepsilon$, there exists a unique value of $\phi^{*}$.

(d) The equilibrium maximizes total welfare (worker's utility + firm profits).

Proof. (a) Differentiating $u(e)$ with respect to e and equating to zero shows that the optimal effort level for the worker is $\mathrm{e}^{*}=\left(\phi^{*}+\varepsilon\right) / 2$.

(b) Substitute $\mathrm{e}^{*}$ in $\mathrm{u}(\mathrm{e})$ to get $\mathrm{u}\left(\mathrm{e}^{*}\right)=\varepsilon_{0}+\phi_{0}+\left(\phi^{*}+\varepsilon-\mathrm{e}^{*}\right) \mathrm{e}^{*}=\varepsilon_{0}+\phi_{0}+\left(\phi^{*}+\varepsilon\right)^{2} / 4$. Since the value of $\phi_{0}$ does not affect the choice of effort by the worker, it is clear that the firm should choose this value so as to give the worker just enough utility to keep him from quitting (the individual rationality constraint is binding). This implies that $\mathrm{u}\left(\mathrm{e}^{*}\right)=\varepsilon_{0}+\phi_{0}{ }^{*}+\left(\phi^{*}+\varepsilon\right)^{2} / 4=$ $\mathrm{U}_{0}$, from which (b) follows immediately.

(c) Substitute $\mathrm{e}^{*}$ and $\phi_{0}{ }^{*}$ in the profit function to get $\pi\left(\phi_{0}{ }^{*}, \phi^{*}, \mathrm{e}^{*}\right)=\mathrm{r}\left(\mathrm{e}^{*}\right)-\phi_{0}{ }^{*}-\phi^{*} \mathrm{e}^{*}=\mathrm{r}\left[\left(\phi^{*}+\right.\right.$ $\varepsilon) / 2]-\mathrm{U}_{0}+\varepsilon_{0}+\left(\phi^{*}+\varepsilon\right)^{2} / 4-\phi^{*}\left(\phi^{*}+\varepsilon\right) / 2=\mathrm{r}\left[\left(\phi^{*}+\varepsilon\right) / 2\right]-\mathrm{U}_{0}+\varepsilon_{0}+\left(\varepsilon^{2}-\left(\phi^{*}\right)^{2}\right) / 4$. Differentiate this function with respect to $\phi$ to get the first-order derivative $\mathrm{r}^{\prime}\left[\left(\phi^{*}+\varepsilon\right) / 2\right] / 2-$ $\phi^{*} / 2$. Equating this to zero yields the result in (c). Notice also that the second-order derivative with respect to $\phi$ evaluated at $\phi=\phi^{*}$ is equal to $\left(\mathrm{r}^{\prime \prime}\left(\left(\phi^{*}+\varepsilon\right) / 2\right) / 2-1\right) / 2$. The restrictions on $\mathrm{r}$ (in particular, that $\mathrm{r}^{\prime \prime}(\mathrm{e})<2$ for all e, see Assumption 1) ensure that a solution to the firstorder condition is the unique maximizer of profits. To see that a solution to the first-order condition exists, let us define $\mathrm{Z}(\phi ; \varepsilon)=2 \partial \pi / \partial \phi=\mathrm{r}^{\prime}[(\phi+\varepsilon) / 2]-\phi$. We have to show that given the value of $\varepsilon$, for some $\phi^{*}$ we have $\mathrm{Z}\left(\phi^{*} ; \varepsilon\right)=0$. If $\mathrm{r}^{\prime}(\varepsilon / 2)=0$ then $\mathrm{Z}(0 ; \varepsilon)=0$, implying that $\phi^{*}=0$. If $\mathrm{r}^{\prime}(\varepsilon / 2)>0$, then $\mathrm{Z}(0 ; \varepsilon)>0$. Since $\mathrm{r}^{\prime}(\mathrm{e}) \leq \mathrm{R}$ for all e by assumption, $\mathrm{Z}(\phi ; \varepsilon)$ approaches $-\infty$ as $\phi$ approaches $\infty$; the continuity of $\mathrm{Z}(\phi ; \varepsilon)$ in $\phi$ then implies that for some $\phi^{*}$ 
we have $\mathrm{Z}\left(\phi^{*} ; \varepsilon\right)=0$.

(d) Total welfare, denoted by W(e), is equal to the worker's utility plus the firm's profits, and therefore is given by:

$\mathrm{W}(\mathrm{e})=\mathrm{u}(\mathrm{e})+\pi\left(\phi_{0}, \phi, \mathrm{e}\right)=\varepsilon_{0}+\varepsilon \mathrm{e}+\phi_{0}+\phi \mathrm{e}-\mathrm{e}^{2}+\mathrm{r}(\mathrm{e})-\phi_{0}-\phi \mathrm{e}=\varepsilon_{0}+\varepsilon \mathrm{e}-\mathrm{e}^{2}+\mathrm{r}(\mathrm{e})$.

Welfare is maximized by the effort that solves the first-order condition: $\varepsilon-2 \mathrm{e}+\mathrm{r}^{\prime}(\mathrm{e})=0$. To see that the equilibrium found above indeed solves this equation, substitute the equilibrium effort $\mathrm{e}^{*}=\left(\phi^{*}+\varepsilon\right) / 2$ in this equation. This yields $-\phi^{*}+\mathrm{r}^{\prime}\left(\left(\phi^{*}+\varepsilon\right) / 2\right)=0$. Since this is exactly the condition for the firm's profit maximization problem in part (c), and since there is a unique value of $\phi^{*}$ that solves this equation, it follows that the equilibrium maximizes total welfare.

Part (a) suggests that effort depends on the external and firm-provided incentives in a symmetric manner, and is not affected by $\varepsilon_{0}$ and $\phi_{0}$ but only by $\varepsilon$ and $\phi$. Part (c) states that $\phi^{*}$ $=\mathrm{r}^{\prime}\left(\mathrm{e}^{*}\right)$, which means that the firm equates the marginal cost of increasing e to its marginal revenue (by choosing $\phi$, the firm implicitly also chooses e). The reason that $\phi^{*}$ is the marginal cost of increasing e, however, is not that $\partial\left(\phi_{0}+\phi^{*} \mathrm{e}\right) / \partial \mathrm{e}=\phi^{*}$, as this ignores both the external incentives and the individual rationality constraint (IRC). The marginal cost of increasing e is the additional amount required to compensate the worker for his increased effort (in order to satisfy the IRC). The worker's marginal disutility from increased effort is 2e. External incentives, however, partially compensate the worker by giving him a marginal utility of $\varepsilon$ for the increased effort. The firm's marginal cost is therefore $2 \mathrm{e}^{*}-\varepsilon$. Since $\mathrm{e}^{*}=\left(\phi^{*}+\varepsilon\right) / 2$, the marginal cost turns out to be exactly equal to $\phi^{*}$.

It also follows from part (c) that if $\mathrm{r}^{\prime}(\mathrm{e})=0$ for all $\mathrm{e}$, then $\phi^{*}=0$ for any $\varepsilon$ : if revenues are not higher when the worker exerts more effort, the firm does not provide the worker any 
incentives to increase effort. This is not because the firm does not have an incentive to increase effort and therefore it does not reward effort; in fact, the firm does have an incentive to increase effort, as this increases the external incentives and thus reduces the amount the firm has to pay the worker. On the other hand, however, increased effort is also costly to the firm because the worker requires to be compensated for his higher effort. When $\mathrm{r}^{\prime}(\mathrm{e})=0$ for all e, these two opposite effects exactly cancel each other, and the firm finds it optimal to choose $\phi^{*}=0$.

The intuition for part (d) that shows that the equilibrium achieves the welfare-maximizing outcome is the following: in equilibrium, the firm extracts all the surplus from the worker by choosing $\phi_{0}$ in a way that gives the worker only his reservation utility of $U_{0}$. Therefore the firm in fact wants to maximize total welfare, because the worker's utility is given by $U_{0}$ and therefore maximizing total welfare also maximizes the firm's profits. Because the firm can implement any desired effort level by the choice of $\phi$, it is able to achieve the welfaremaximizing outcome.

A main question of interest is how external incentives affect the optimal firm-provided incentives. Intuitively, we might think that more external incentives reduce the amount of incentives the firm chooses to provide, implying that $\phi^{*}$ is decreasing in $\varepsilon$. Interestingly, as the following proposition suggests, this intuition is not always true.

Proposition 2. $\phi_{\varepsilon}^{*} \equiv \partial \phi^{*} / \partial \varepsilon=r^{\prime \prime}\left(e^{*}\right) /\left[2-r^{\prime \prime}\left(e^{*}\right)\right]>-1$. It follows that the sign of $\phi_{\varepsilon}^{*}$ is the same as the sign of $r^{\prime \prime}\left(e^{*}\right)$.

Proof. Part (c) of Proposition 1 states that $\phi^{*}=r^{\prime}\left(e^{*}\right)$. Differentiate both sides with respect to $\varepsilon$, and substitute $\partial \mathrm{e}^{*} / \partial \varepsilon=\left(1+\phi_{\varepsilon}^{*}\right) / 2$ to get $\phi_{\varepsilon}^{*}=\mathrm{r}^{\prime \prime}\left(\mathrm{e}^{*}\right)\left(1+\phi_{\varepsilon}^{*}\right) / 2$. Multiplying both sides by two and rearranging yields $\phi_{\varepsilon}^{*}=\mathrm{r}^{\prime \prime}\left(\mathrm{e}^{*}\right) /\left[2-\mathrm{r}^{\prime \prime}\left(\mathrm{e}^{*}\right)\right]$. By assumption, $\mathrm{r}^{\prime \prime}(\mathrm{e})<2$ for all e, so the denominator is positive, and the sign of $\phi_{\varepsilon}^{*}$ is equal to the sign of $\mathrm{r}^{\prime \prime}\left(\mathrm{e}^{*}\right)$. When $\mathrm{r}^{\prime \prime}\left(\mathrm{e}^{*}\right)<0$, the 
numerator is smaller in absolute value than the denominator, implying that $\phi_{\varepsilon}^{*}$ is always bigger than -1 .

Since we only assumed that $\mathrm{r}^{\prime \prime}(\mathrm{e})<2$, the sign of $\phi_{\varepsilon}^{*}$ can be either negative, positive, or zero, depending on $\mathrm{r}^{\prime \prime}\left(\mathrm{e}^{*}\right)$, and is therefore not necessarily negative as the intuition above suggested. When $\varepsilon$ is increased, this reduces the amount of incentives the firm has to provide the worker in order to retain the same effort level, as can be seen from the equation $\mathrm{e}^{*}=\left(\phi^{*}+\right.$ $\varepsilon) / 2$. But at the same time, higher $\varepsilon$ makes it cheaper for the firm to increase effort, because external incentives are contributing more to compensate the worker for the increased effort. This makes the optimal effort to implement higher, and acts to increase the optimal value of $\phi$. Which of these two opposite effects dominates depends on the sign of $\mathrm{r}^{\prime \prime}\left(\mathrm{e}^{*}\right)$.

How do equilibrium effort, revenues, and profits depend on the amount of external incentives? The following proposition suggests that all of them are increasing in $\varepsilon$ :

Proposition 3. (a) $\partial e^{*} / \partial \varepsilon=1 /\left[2-r^{\prime \prime}\left(e^{*}\right)\right]>0$,

(b) $\partial r / \partial \varepsilon=\phi^{*} /\left[2-r^{\prime \prime}\left(e^{*}\right)\right] \geq 0$,

(c) $\partial \pi / \partial \varepsilon=e^{*} \geq 0$.

Proof. (a) $\partial \mathrm{e}^{*} / \partial \varepsilon=\partial\left[\left(\phi^{*}+\varepsilon\right) / 2\right] / \partial \varepsilon=\left(\phi^{*}{ }_{\varepsilon}+1\right) / 2=\left\{\mathrm{r}^{\prime \prime}\left(\mathrm{e}^{*}\right) /\left[2-\mathrm{r}^{\prime \prime}\left(\mathrm{e}^{*}\right)\right]+1\right\} / 2=1 /\left[2-\mathrm{r}^{\prime \prime}\left(\mathrm{e}^{*}\right)\right]>$ 0 .

(b) $\partial \mathrm{r} / \partial \varepsilon=\mathrm{r}^{\prime}\left(\mathrm{e}^{*}\right) \partial \mathrm{e}^{*} / \partial \varepsilon=\mathrm{r}^{\prime}\left(\mathrm{e}^{*}\right) /\left[2-\mathrm{r}^{\prime \prime}\left(\mathrm{e}^{*}\right)\right]=\phi^{*} /\left[2-\mathrm{r}^{\prime \prime}\left(\mathrm{e}^{*}\right)\right] \geq 0$, where the equalities follow from part (a) of this proposition and part (c) of Proposition 1.

(c) Using the expression for profits derived in the proof of part (c) of Proposition 1 and then part (b) of the current proposition, we get $\partial \pi / \partial \varepsilon=\partial\left[\mathrm{r}\left(\mathrm{e}^{*}\right)-\mathrm{U}_{0}+\varepsilon_{0}+\left(\varepsilon^{2}-\phi^{*^{2}}\right) / 4\right] / \partial \varepsilon=\phi^{*} /[2$ $\left.-r^{\prime \prime}\left(e^{*}\right)\right]+\varepsilon / 2-\phi_{\varepsilon}^{*}\left(\phi^{*} / 2\right)$. Using Proposition 2 to substitute for $\phi_{\varepsilon}^{*}$ and simplifying we then 
get $\partial \pi / \partial \varepsilon=\phi^{*} /\left[2-\mathrm{r}^{\prime \prime}\left(\mathrm{e}^{*}\right)\right]+\varepsilon / 2-\left(\phi^{*} / 2\right) \mathrm{r}^{\prime \prime}\left(\mathrm{e}^{*}\right) /\left[2-\mathrm{r}^{\prime \prime}\left(\mathrm{e}^{*}\right)\right]=\left(\phi^{*}+\varepsilon\right) / 2=\mathrm{e}^{*}$.

Part (a) of the proposition suggests that regardless of the direction in which the firmprovided incentives go, effort is always increasing in $\varepsilon$. This is a direct consequence of the previous result that $\phi_{\varepsilon}^{*}>-1$, which in turn implies that when $\varepsilon$ increases, the total slope of the incentives that the worker faces, $\phi^{*}+\varepsilon$, also increases (even if $\phi^{*}$ decreases). Part (c) suggests that except for a very special case (both $\phi^{*}$ and $\varepsilon$ being zero), the firm's profits are increasing in the amount of external incentives. This means that firms should try to increase the amount of external incentives that the worker faces (if they can do so and it is not too costly), as I discuss in more detail in the next section.

\section{Conclusion}

The article explores how the optimal choice of firm-provided incentives is affected by external incentives that the worker faces, such as satisfaction from working well or improving his reputation and thus his prospects with other employers. Surprisingly, an increase in external incentives does not necessarily reduce the optimal amount of incentives that the firm should offer. Whether the firm should increase, decrease, or retain its incentive slope (i.e., how strongly it rewards effort) following a change in external incentives turns out to depend on the second-order derivative of the revenue function with respect to effort.

The model also shows that the firm's profits are increasing in the amount of external incentives, suggesting that the firm should try to increase the external incentives its workers face. For example, the firm can attempt to increase the sensitivity of the worker's satisfaction to his performance level, thus increasing the slope of his external incentives. This might increase his effort and yield higher profits. There are several ways the firm can try to achieve 
this goal.

One way is to provide workers with more feedback on the quality of their work and their performance level compared to various benchmarks. ${ }^{8}$ Another way is through peer pressure (for theoretical analyses of related issues see Kandel and Lazear, 1992; Barron and Paulson Gjerde, 1997). Workers often care about what others around think about them, and this can be used to encourage them to work well.

There are several ways to increase the external incentives that result from peer pressure. One is to make the evaluations of workers' performance public. For example, when the teaching evaluations of professors are distributed to the entire department, this creates more pressure to avoid low evaluations than if each professor only receives his own evaluations. Another way is to give collective bonuses, i.e., bonuses that depend not only on the worker's effort but also on a bigger group's performance. Then workers have an incentive to encourage others to work harder, and those who do not work hard might be perceived as free riders. This can increase the peer pressure to increase effort and work well. A third way is to make workers care more about what other workers think about them. The firm might be able to do so by fostering the social interactions between the workers, for example by organizing sport events and vacations in which employees interact with each other. People care more about what their friends think about them than about what strangers think, so fostering the relationships between the employees might increase the potential of peer pressure to improve workers' performance. ${ }^{9}$

\footnotetext{
${ }^{8}$ As an anonymous referee pointed out, however, this should be done carefully, especially when the worker is involved in a long-term project and his progress cannot be evaluated accurately before the project is completed.

${ }^{9}$ Such measures, however, could also be counter-productive if by knowing better his colleagues the worker will respect them less, or if it will allow workers to collusively reduce effort, not monitoring each other as carefully as they would as strangers. I thank an anonymous referee for this idea.
} 


\section{References}

Barron, J.M., and Paulson Gjerde, K., 1997. Peer pressure in an agency relationship. Journal of Labor Economics 15, 234-254.

Bernheim, B.D., and Whinston, M.D., 1982. Common agency. Econometrica 54, 923-942.

Holmstrom, B., 1982. Moral hazard in teams. The Bell Journal of Economics 13, 324-340.

Holmstrom, B., and Milgrom, P., 1991. Multitask principal-agent analyses: incentive contracts, asset ownership, and job design. Journal of Law, Economics and Organization 7, 24-52.

Kandel, E., and Lazear, E.P., 1992. Peer pressure and partnerships. Journal of Political Economy 100, 801-817.

Mookherjee, D., 1984. Optimal incentive schemes with many agents. The Review of Economic Studies 51, 433-446.

Rogerson, W.P., 1985. Repeated moral hazard. Econometrica 53, 69-76. 